\title{
STS Currents against the "Anti-Science" Tide
}

\author{
ABBY J. KINCHY ${ }^{1}$ \\ RENSSELAER POLYTECHNIC UNIVERSITY
}

\begin{abstract}
This essay considers some possible relationships that STS scholars can have with activists who are resisting attacks on environmental science. STS scholars can document the counter-currents to the "anti-science" moment, work in partnership with activists outside of academia, use access to institutional resources to give environmental movements strength, use STS research to help activists better understand the policy process and the history of science funding, and help people to develop a sociological imagination about science and the environment.
\end{abstract}

\section{Keywords}

social movements; activism; politics; climate; environment

My research deals with the politics of environmental science, and the last few years have been a particularly alarming time to work in this space. We have seen the further institutionalization of climate change denial, the erasure of public datasets, censorship of scientists, and the reduction of scientific staff at EPA and other agencies. ${ }^{2}$ As STS scholars, I think it is important that we not just observe these changes, but also oppose them, in our words and actions. But it is not always clear what kinds of interventions are most effective. We are in need of deeper conversations about what it means to do engaged STS scholarship right now. For example, should we be thinking about immediate, short-term actions, or long-term transformations? How do we use our unique positions as STS scholars to advocate for environmental science and scientists, without uncritically giving wholesale support for all environmental research practices? And how and where should we intervene? In this short essay, I will reflect on my own experiences to suggest some ways to approach these questions.

I'm particularly interested in our potential relationships to the myriad forms of collective action that seem to be going against the so-called "anti-science" tide. Along with the rise of Trump, we have also seen the emergence of the March for Science, which has been campaigning on multiple issues since 2017 (https://marchforscience.org/). There is also the Environmental

Abby J. Kinchy, Email: Kincha@rpi.edu

2 The Silencing Science Tracker, a joint initiative of the Sabin Center for Climate Change Law and the Climate Science Legal Defense Fund, has tracked "government attempts to restrict or prohibit scientific research, education or discussion, or the publication or use of scientific information," since the November 2016 election. On September 19, 2019, there were 377 entries. http: / / columbiaclimatelaw.com/resources/ silencing-science-tracker/

Copyright (C) 2020 (Abby J. Kinchy). Licensed under the Creative Commons Attribution Non-commercial No Derivatives (by-nc-nd). Available at estsjournal.org. 
Data and Governance Initiative, or EDGI, which rapidly organized to archive federal environmental data and websites that were being erased (https: / envirodatagov.org/). We have seen the resurgence of Science for the People, a radical scientists' movement campaigning on multiple issues, including a Green New Deal, labor rights, and anti-militarism (https: / scienceforthepeople.org/). In addition, while this pre-dates the Trump Administration, we continue to see enthusiasm for citizen science-participatory research-at universities and in environmental movements (https://scistarter.org/). Where do STS scholars stand in relation to these forms of resistance to attacks on environmental science?

One possible role is to document and amplify the counter-currents to the "anti-science" moment. In my case, I just finished writing a book that is about and for people who lead and participate in environmental citizen science (Kimura and Kinchy 2019). My co-author and I focused on dilemmas that were commonly experienced across different examples of citizen science, so that citizen scientists could learn from each other about how to navigate them successfully. For example, community groups that engage in environmental science often experience tensions around the question of volunteering to do work that professional scientists would be paid to do. Citizen scientists are often commended for observing pollution that regulatory officials overlook; yet some water monitoring volunteers that I interviewed were frustrated that they were "doing what the state should be doing." For organizers of citizen science projects, then, it is particularly important to ensure that such efforts are not merely unpaid replacements for absent regulatory science, but opportunities for participants to find their collective voice and advocate for themselves. Ethnographic studies like this can be of value to those who are resisting attacks on environmental science, if they want their efforts and perspectives to be documented; however, this is not always the case. Activists may not want to be studied, or may find the research process to be extractive. Activists may prefer that you "study up" instead, and investigate their more powerful opponents.

Beyond studying up, engaged STS may also mean directly advocating for change, working in partnership with activists outside of academia. For example, many of my STS colleagues are deeply involved in EDGI and regard this as part of their scholarly identities. EDGI's mission of "environmental data justice" reflects longstanding principles of environmental justice as well as theories from feminist STS and critical data studies (Dillon et al. 2019; Walker et al. 2018). In contrast, STS scholars may be reluctant to join some other campaigns, such as the March for Science, because of disagreement with how that movement frames science as a guide to policy. For instance, sociologists considered their participation in the March for Science in Sociological Forum in 2017. Robert Brulle focused on the march's problematic response to efforts to delegitimize climate science. He observed that

the goal of the climate countermovement is to displace the real debate about what we should do to address climate change into the scientific realm. This allows for a continuous debate about the correctness of climate science, which the media and political process is unable to resolve. Countering scientific disinformation with scientific information [as advocated by the March for Science] merely repeats and continues this nonsense debate (Brulle 2018, 257). 
STS scholars are well equipped to recognize the scientization of climate politics, and may have a hard time finding common cause with those who naïvely advocate value-free science. On the other hand, perhaps our more active, collective participation in the March for Science (or affiliated local events) would help to shift the frames.

A different way to engage is to facilitate and advise. We can use our access to institutional resources to give environmental movements strength and we can use our research as STS scholars to help them better understand the policy process or the history of science funding. For example, last year, a colleague and I organized a workshop on Citizen Science in Agri-Food Systems. As university researchers, we were able to secure NSF funds to support the event. We used these funds to bring together professional scientists and community activists from across North America who were using participatory research methods in pursuit of food justice. One of the things the workshop accomplished was to compile a report on the institutional obstacles to university-community collaboration, as experienced by the participants (Kimura and Kinchy 2018). We expect to use this report to advocate for improved funding for participatory, community-based research. A similar approach could be used to fund and organize workshops and seminars on other themes that bring together environmental activists and scientists, building social ties and deepening knowledge that is needed for long-term social movement organizing.

Finally, I think that an important role that STS scholars can have right now is to help people to develop a sociological imagination about science and the environment. Sociological imagination refers to a quality of mind that grasps "the interplay of [individuals] and society, of biography and history, of self and world" (Mills [1959] 2000, 4). In the first chapter of The Sociological Imagination, C. Wright Mills makes a statement that seems oddly relevant to our current moment. While explaining why ordinary people in 1959 needed a sociological imagination, he writes:

It is not only information that they need-in this Age of Fact, information often dominates their attention and overwhelms their capacities to assimilate it. It is not only the skills of reason that they need... What they need, and what they feel they need, is a quality of mind that will help them to use information and to develop reason in order to achieve lucid summations of what is going on in the world and of what may be happening within themselves (Mills [1959] 2000, 5).

One might rightfully question whether "Age of Fact" accurately describes our current moment (see every previous STS commentary on "post-truth"). Yet many of Trump's opponents seem to long for an Age of Fact. Science Marchers call on decision-makers to follow the advice of scientists more faithfully. Citizen science projects trumpet their successes at producing unprecedented amounts of environmental data. EDGI's original mission is to preserve information.

But people do not just need facts and information. They need a quality of mind that helps them to use this information to make sense of and make change in the world. Activists who are resisting attacks on the environmental regulatory state need a sociological imagination to grasp 
the historical and structural reasons for these troubles. Failing this, they misattribute the current problems to "anti-science" individuals-the people who supposedly don't "listen to science"rather than broader economic forces and corporate interests. As Tim Wise wrote in a recent essay, "We lack the sociological imagination needed to analyze the power dynamics that make polluting industries so powerful, and the historical memory that might allow us to learn from past struggles against corporate irresponsibility as we fight for a healthier future" (Wise 2019).

As STS scholars, I hope that we are in the position to help cultivate the quality of mind needed for more effective collective efforts to defend environmental protections and research. We can begin to do this by interpreting and historicizing events and raising questions that others aren't asking, both in our classrooms and in public. For instance, I was asked to speak on a local March for Science panel. In that forum, I indicated that the problems we are facing are not new or unique; in fact, under the George W. Bush Administration, we were having many of the same conversations about "politicized" science and censorship of scientists who are critical of industry (Kinchy and Kleinman 2005). When we historicize and contextualize the "anti-science" moves we are witnessing today, it becomes evident that we are facing not just a short-term electoral fight, but a longer struggle for control over powerful industrial actors.

Many strands of STS have grown out of social movements (feminist, antinuclear, antiracist, and so on), and social movements are of recurring interest in STS research (Breyman et al. 2017). We can draw upon this rich tradition as we seek our place in the counter-currents running against the Trump Administration's myriad attacks on environmental science and regulation. There is a lot of work to do, and so much that we can contribute.

\section{Author Biography}

Abby Kinchy is a sociologist and associate professor in the Department of Science and Technology Studies at Rensselaer Polytechnic Institute in Troy, New York. She is the author of Science by the People: Participation, Power, and the Politics of Environmental Knowledge (Rutgers, 2019). Her current research explores collaborative, community-based approaches to studying urban soil contamination.

\section{Acknowledgements}

This essay originated as a presentation at the annual meetings of the Eastern Sociological Society in March 2019, and benefited from the comments shared by my fellow panelists, the audience, and the session organizer, Laurel Smith-Doerr. I also wish to thank Nancy Campbell, Guy Schaffer, Daniel Kleinman, Laura Senier, Katie Vann, and an anonymous reviewer for their critiques and encouragement. 


\section{References}

Breyman, Steve, Nancy Campbell, Virginia Eubanks, and Abby Kinchy. 2017. "STS and Social Movements: Pasts and Futures" in the Handbook of Science and Technology Studies, Fourth Edition. pp. 289-318 Cambridge: The MIT Press.

Brulle, Robert J. 2018. "Critical Reflections on the March for Science." Sociological Forum 33 (1): 255-58. https: / / doi.org/10.1111/ socf.12398.

Dillon, Lindsey, Rebecca Lave, Becky Mansfield, Sara Wylie, Nicholas Shapiro, Anita Say Chan, and Michelle Murphy. 2019. "Situating Data in a Trumpian Era: The Environmental Data and Governance Initiative." Annals of the American Association of Geographers 109 (2): 545-55. https: / / doi.org/10.1080/24694452.2018.1511410.

Kimura, Aya H., and Abby Kinchy. 2018. "Citizen Science in North American Agri-Food Systems: Lessons Learned." Honolulu, HI. https://sih.berkeley.edu/research-project/citizenscience-in-agri-food-systems-lessons-and-recommendations/.

- 2019. Science by the People: Participation, Power, and the Politics of Environmental Knowledge. New Brunswick, NJ: Rutgers University Press.

Kinchy, Abby J, and Daniel Lee Kleinman. 2005. "Democratizing Science, Debating Values." Dissent Summer.

Walker, Dawn, Eric Nost, Aaron Lemelin, Rebecca Lave, and Lindsey Dillon. 2018. "Practicing Environmental Data Justice: From DataRescue to Data Together." Geo: Geography and Environment 5 (2): e00061. https: / / doi.org/10.1002/ geo2.61.

Wise, Tim. 2019. "Forget STEM, We Need MESH: The importance of media literacy, ethics, sociology and history education." Medium-Our Human Family (17 September) https: / / medium.com/ our-human-family/ forget-stem-we-need-mesh-43ab6f6273cd.

Accessed 19 September 2019. 